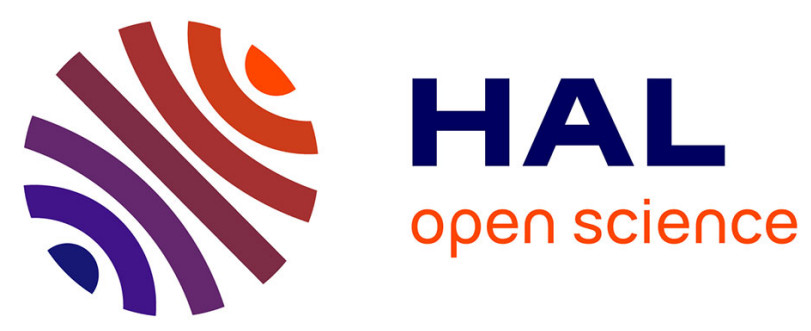

\title{
Socioeconomic status and site-specific cancer incidence, a Bayesian approach in a French Cancer Registries Network study
}

Josephine Bryere, Olivier Dejardin, Ludivine Launay, Marc Colonna, Pascale Grosclaude, Guy Launoy

\section{To cite this version:}

Josephine Bryere, Olivier Dejardin, Ludivine Launay, Marc Colonna, Pascale Grosclaude, et al.. Socioeconomic status and site-specific cancer incidence, a Bayesian approach in a French Cancer Registries Network study. European Journal of Cancer Prevention, 2016, 00, pp.0 - 000. 10.1097/CEJ.0000000000000326 . hal-02363581

\section{HAL Id: hal-02363581 \\ https://hal.science/hal-02363581}

Submitted on 4 Dec 2019

HAL is a multi-disciplinary open access archive for the deposit and dissemination of scientific research documents, whether they are published or not. The documents may come from teaching and research institutions in France or abroad, or from public or private research centers.
L'archive ouverte pluridisciplinaire HAL, est destinée au dépôt et à la diffusion de documents scientifiques de niveau recherche, publiés ou non, émanant des établissements d'enseignement et de recherche français ou étrangers, des laboratoires publics ou privés. 
SOCIOECONOMIC STATUS AND SITE-SPECIFIC CANCER INCIDENCE

A BAYESIAN APPROACH IN A FRENCH CANCER REGISTRIES NETWORK STUDY

Joséphine Bryere ${ }^{a}$, Olivier Dejardina, Ludivine Launay ${ }^{a}$, Marc Colonna ${ }^{\mathrm{b}, \mathrm{d}}$, Pascale Grosclaude ${ }^{\mathrm{c}, \mathrm{d}}$, Guy Launoy ${ }^{\mathrm{a}, \mathrm{d}}$, and French Network of Cancer registries (FRANCIM).

a U1086 INSERM-UCBN, “Cancers \& Preventions”, Equipe labellisée Ligue Contre le Cancer, Caen, France

${ }^{b}$ Registre des cancers de l'Isère, $\mathrm{CHU}$, Grenoble, France

${ }^{\mathrm{c}}$ Registre des cancers du Tarn, Institut Claudius Regaud, Toulouse, France

${ }^{\mathrm{d}}$ Réseau Français des Registres des Cancers, Faculté de médecine, Toulouse, France

Corresponding author: Joséphine Bryere, "Cancers \& Préventions" U1086 INSERM-UCBN, Centre

François Baclesse, Avenue Général Harris, 14076 Caen, France, Tel: +33(0)231458611, Fax: +33(0)231458630, email: josephine.bryere@inserm.fr

Running head : Socioeconomic status and cancer incidence

Funding: This work was supported by Institut National de la Sante et de la Recherche Médicale, the Basse-Normandie regional government and the Ligue Nationale Contre le Cancer.

Conflict of interest: None declared 


\section{Abstract}

Objectives The objective of this study was to identify and compare cancer sites whose incidence is influenced by social deprivation.

Methods The study population comprised 189144 cases of cancer diagnosed between 2006 and 2009, recorded in member registries of the French Network of Cancer Registries. Social environment was assessed at an aggregate level using the European Deprivation Index (EDI). The association between incidence and socioeconomic status was assessed by a geographical Bayesian Poisson model permitting to reduce the overall variability and to smooth the relative risks by sharing information provided by multiple geographic units.

Results For cancers of the stomach, liver, lips-mouth-pharynx and lung, a higher incidence in deprived populations was found for both sexes as well as for cancers of the larynx, esophagus, pancreas and bladder in males and cervical cancer in females. For melanoma, prostate, testis, ovarian and breast, a higher incidence in affluent populations was observed. The highest relative risks of the lowest social class compared with the highest social class were found for larynx ( $R R=1.67$ [1.43;1.95]), lips-mouthpharynx ( $R R=1.89$ [1.72;2.07]) and lung $(R R=1.59$ [1.50;1.68]) in males and for cervix ( $R R=1.62$ $[1.40 ; 1.88])$ and lips-mouth-pharynx (RR=1.56 [1.30;1.86]) in females.

Conclusions By estimating the burden of social deprivation on cancer incidence throughout France, this study enables us to measure the gains that could be obtained by implementing targeted prevention efforts.

Keywords: Cancer incidence, Deprivation, Social environment, Site-specific approach, Cancer registries, Bayesian modeling

\section{Introduction}

For many years, large health inequalities have been observed in developed countries, even in countries that have egalitarian health systems. These inequalities find their means of expression through various chronic diseases such as cardiovascular disease, respiratory disease, diabetes, cancer and many others. In France, cancer is the cause of death that best reveals the social inequalities in health (Mackenbach et al., 2008). Continual observation of the relationship between socioeconomic status and cancer mortality is a fundamental tool for public surveillance and implementation of preventive measures. In France, one of the priorities announced in the Cancer Plan 2014--2019 is to "study the geographical 
and socioeconomic disparities in incidence and survival of cancer using social deprivation indices" (Plan Cancer 2014-2019).

Concerning social disparities in cancer incidence, some relationships going in both directions are already well known. Cancer sites associated with low social status usually include lung (Eberle et al., 2010; Hystad et al., 2013; Hwang et al., 2013; Boscoe et al., 2014; Sharpe et al., 2014) upper aerodigestive tract (Dalton et al., 2008; Eberle et al., 2010; Boscoe et al., 2014; Sharpe et al., 2014), liver (Boscoe et al., 2014; Sharpe et al., 2014), cervix (Dalton et al., 2008; Benard et al. 2008; Eberle et al., 2010; Boscoe et al., 2014), bladder (Eberle et al., 2010), stomach (Dalton et al., 2008; Boscoe et al., 2014) and esophagus (Dalton et al., 2008; Levi et al., 2013; Boscoe et al., 2014); those associated with high social level include breast (Robert et al., 2004; Dalton et al., 2008; Eberle et al., 2010; Boscoe et al., 2014), prostate (Dalton et al., 2008; Cheng et al., 2009; Eberle et al., 2010; Boscoe et al., 2014) and melanoma (Dalton et al., 2008; Eberle et al., 2010; Hausauer et al., 2011 ; Boscoe et al., 2014). However, few studies examining the relationship between socioeconomic status and cancer incidence have been conducted in Europe, and existing studies often covering only one specific site. From a public health point of view, it is important to compare the extent of the influence of social deprivation on the incidence of various cancers, to implement those preventive measures that will have the greatest impact on public health.

Measuring and comparing the impact of social deprivation on cancer incidence between countries and over time will facilitate development of more efficient national and supranational policies to tackle social inequalities. Such comparison requires reliable, accurate and comparable data on the cancer incidence and socioeconomic environment of the population. Regarding incidence, the increasing international standardization of rules for cancer registration creates valuable data provided by cancer registries, for use now and in the future. With respect to socioeconomic environment, because individual socioeconomic data are often absent or poorly collected in routine health databases, individual social status is often assessed using socioeconomic characteristics of the place of residence 
(Krieger et al., 1997). Townsend demonstrated the relevance of the concept of relative deprivation and the necessity of taking into account both the objective and subjective dimensions of poverty (Townsend, 1987). From a European perspective, the recent European Deprivation Index (EDI), which incorporates such concepts into its construction, permits socioeconomic environment measures to be compared or at least makes them transferable between different European countries, despite sociocultural differences (Pornet et al., 2012). Moreover, when patient addresses are available, the EDI is usable at the smallest geographic level for which census data are available. In France, patient addresses have been routinely recorded in cancer registries since 2006, thereby enabling, after geocoding, examination of the relationship between social environment and cancer incidence and its evolution over time, at a very small geographic scale.

The objective of this study was to investigate the link between socioeconomic environment and incidence for the 15 most frequent solid tumors and three most frequent hematopoietic malignancies in France by using a Bayesian model taking into account the geographic nature of the data.

\section{Methods}

\section{Study population}

The study population consisted of all diagnosed cancer cases that were recorded in member registries of the French Network of Cancer Registries (FRANCIM) between 1 January 2006 and 31 December 2009. The population of the area covered by the registries was about 12 million people ( 5778595 men and 6137751 women), representing 20\% of the French population. For the general registries of Gironde and Lille and its region only cancer cases diagnosed between 1 January 2008 and 31 December 2009 were analyzed (no data were available before this date). For reasons of statistical power, only the 15 most frequent solid tumors and the three most frequent hematopoietic malignancies in men and women were analyzed (Table 1). These sites were determined using an estimate of the incidence of cancer for France (Binder-Foucard et al., 2013). The quality and completeness of records of member 
registries of the FRANCIM network are evaluated every 4 years by the National Committee of Registries. The quality of French registry data is regularly checked by international authorities (IARC; International Association of Cancer Registries) for international studies (EUROCARE, CONCORD). The cancer sites considered were defined according to codes of the International Classification of Diseases for Oncology, $3^{\text {rd }}$ Edition (ICD-O-3; Table 1). The total population included 189144 cancer cases (Table 1).

\section{Data}

For all diagnosed cancers, patient addresses were geolocalized using Geographic Information Systems (ArcGIS 10.2) and assigned to an IRIS, a geographical area defined by INSEE (Institut National de la Statistique et des Etudes Economiques). An IRIS is the smallest geographic unit for which census data are available, an essential factor in this type of study to minimize ecological bias (Krieger et al., 2002). The study area included 9740 IRIS. The municipalities of at least 10000 inhabitants and a high proportion of municipalities from 5000 to 10000 inhabitants were divided into IRIS. Each IRIS included approximately 2000 individuals with relatively homogeneous social characteristics. It was built from geographical and statistical criteria and, if possible, each IRIS had to be homogeneous from the perspective of the habitat.

The reference populations came from the INSEE national census in 2006, 2007, 2008 and 2009. These were given for each IRIS, each sex and each age group: (0-14, 15-29, 30-44, 45-59, 60-74, 75 and more).

The French version of the European Deprivation Index (EDI) based on the 2007 national census was used to assign a deprivation score to each IRIS (Pornet et al., 2012). The methodology used an individual deprivation indicator from the conceptual definition of deprivation and selected ecological census variables that are the most closely related to the individual deprivation indicator in the European Union Statistics on Income and Living condition (EU-SILC). The continuous version or the categorical version (national quintiles) of the EDI was used alternatively according to the method used. Regarding the national quintiles, $23.77 \%$ of the study population was in quintile 1 (least deprived), 
$21.06 \%$ was in quintile $2,20.24 \%$ was in quintile $3,18.22 \%$ was in quintile 4 and $16.71 \%$ of the study population was in quintile 5 (most deprived) meaning that the study population was less deprived than the national population.

\section{Statistical analysis}

A Bayesian approach was used rather than a classical Poisson regression because this allowed the integration of extra-Poisson variability if it existed in the data (Pascutto et al., 2000; Colonna, 2002). Using the classical Poisson model in the aggregate geographical studies, as has been done for existing studies, may cause an underestimation of the standard error because overdispersion defined as variability in the number of cases higher than expected by the Poisson distribution is not taken into account. The differences in population sizes between IRIS units, called unstructured spatial heterogeneity, may have introduced variations; this methodology permitted the distinction between random fluctuations and true variations in incidence rates. Moreover, neighboring areas could not be independent and had similar incidence rates. This phenomenon, called spatial autocorrelation, was also integrated with the Bayesian analysis using WinBUGS version 1.4. We estimated the regression coefficient associated with the variable EDI and its $95 \%$ credible interval. A positive parameter related to EDI means an over-incidence in disadvantaged areas, and a negative parameter related to EDI means an over-incidence in favored areas. The analysis was conducted by department and for all available data. To determine whether spatial autocorrelation and spatial heterogeneity were actually present in the data, we first performed the Moran test (Wakefield et al., 2000) for autocorrelation and the Potthoff-Whittinghill (Potthoff and Whittinghill, 1966) test for heterogeneity. These were done using packages spdep and DCluster from R version 2.15.0. According to the results of the tests, we applied a Besag-York- Mollié (BYM) model integrating the two components or a conditionnal autoregressive (CAR) model integrating the spatially structured heterogeneity or a model with the non-spatially structured heterogeneity. If both tests were non-significant, meaning that there was no variability of incidence in the data, the EDI was not included in the analysis. We performed this analysis first using 
first the continuous version of the EDI and then the categorical version of the EDI, to detect if a nonlinear trend existed. For the categorical analysis, the less deprived category was considered the reference category.

\section{Results}

A total 189144 cancer cases were analyzed, with 100299 men and 78845 women. These cancers were divided according to the 16 analyzed departments.

Tables 2 and 3 present the results of analysis using the continuous version of the EDI obtained with all available data. The Potthoff-Whittinghill test was non-significant for the majority of sites in both sexes. Moran test was significant for all sites in both males and females, which confirms a geographical structure in the data and justified modeling. A statistically significant higher incidence among disadvantaged individuals was observed for cancers of the stomach, liver, lips-mouth-pharynx and lung in both sexes. This significant over-incidence was also found for cancers of the larynx, esophagus, pancreas and bladder in men and for cervical cancer in women. A significantly higher incidence in advantaged individuals was observed for melanoma in both sexes. This significant over-incidence was also found for prostate and testicular cancers in men, and ovarian and breast cancers in women. By examining the values of the coefficient estimates associated with the EDI variable, this link between deprivation and incidence was particularly strong for cancers of the larynx, lips-mouth-pharynx and lung and for melanoma (with a negative sign) in men, and for cancers of the cervix, stomach, liver, lipsmouth-pharynx and for melanoma (with a negative sign) in women.

Supplementary Tables S1 and S2 summarize the analysis results for each department in males and females. For stomach, liver, lips-mouth-pharynx and lung sites, for which a significant positive association with deprivation was found in the global analysis, the trend was similar in the majority of areas. Similar observation was made for melanoma, prostate and breast with a negative association. A negative association manner was found for ovary and thyroid for females in a majority of areas but 
never in a significant manner, with a similar observation made for the central nervous system in males. Conflicting results, with positive and negative association depending on area, were found for colonrectum, pancreas, kidney, bladder and hematopoietic sites.

Tables 4 and 5 present the results of analysis using the categorical version of the EDI (estimation and 95\% credible interval). Figure 1 graphically represents the relative risks of the most disadvantaged group (under the fifth quintile of the EDI) compared with the most favored group (above the first quintile of the EDI). Relative risk was more than 1.5 for lips-mouth-pharynx, larynx and lung sites in males, and for cervix and lips-mouth-pharynx in females; the other significant relative risk were found for liver and stomach sites in both sexes. Melanoma exhibited the highest inverse relative risk with deprivation for both sexes, with ovary, breast, and prostate being the other sites inversely associated in a significant way; the testis site was borderline.

\section{Discussion}

Based on data from the national network of cancer registries gathering standardized data from 16 different departments, our results provide a comprehensive assessment of the relationship between socioeconomic status and cancer incidence in France for 18 cancer sites. In men, eight sites were associated with social deprivation, and three sites associated with social affluence; corresponding figures were five sites and three sites in women. The relative risks were particularly strong for cancers of the larynx, lips-mouth-pharynx, esophagus, lung and cervix; those associated with social affluence were strong for melanoma and ovarian cancer. The impact of deprivation on cancer incidence was more important in males than in females. Even if the association with social environment was slight, because of their high incidence, prostate and breast cancers exhibited a high number of excess cases associated with social affluence.

Not surprisingly, cancers related to smoking, alcohol use and infections were found in excess in deprived populations. Such risky behaviors are more common in socially disadvantaged areas 
(Shohaimi et al., 2004; Adimora and Schoenbach, 2005; Baumann et al., 2007; Meffre et al., 2010; Lakshman et al., 2011) and may explain the over-incidence of cancers of the lung, upper aerodigestive tracts, liver, bladder, cervix, stomach and esophagus. The link between deprivation and pancreatic cancer risk is less documented, but the same risk factors exist, i.e., tobacco use, infections and food quality (Maisonneuve and Lowenfels, 2014). Our results showed an over-incidence of other cancers in favored areas, such as prostate, breast and melanoma. For breast cancer and melanoma, such overincidence can be partly explained by the social determinants of some risk factors, such as older age at birth of first child for breast cancer and exposure to UV radiation for melanoma. Importantly for prostate cancer, and to a lesser extent for breast cancer, the over-incidence is explained by the greater adherence in favored populations to screening, which leads to over-diagnosis (Morgan et al., 2013); over-diagnosis is defined as the detection of asymptomatic tumors that would not have been detected without a screening test and would not have caused symptoms, morbidity or death during a person's lifetime. The link between ovarian and testicular cancer risk and social affluence is less documented. Risk factors for ovarian cancer are strongly linked to reproductive risk factors, including older age at birth of first child, a smaller number of children and short periods of breastfeeding (Cramer, 2012). Risk factors for breast cancer, which are partly socially determined, can explain the over-incidence in the affluent population. Knowledge about the epidemiology of testicular cancer is even more uncertain; risk factors being investigated include certain exposures during pregnancy or infancy, certain occupations such as firefighting, or exposure to certain pesticides (McGlynn and Trabert, 2012). Recent studies have highlighted the relationship between social affluence and risk of developing testicular cancer (Schmeisser et al., 2013; Boscoe et al., 2014) but have not provided concrete explanations about the origin of such a relationship. Concerning colorectal cancer, previous studies show conflicting results. Some have found that the incidence of this cancer is associated with lower social class (Aarts et al., 2010; Boscoe et al., 2014) which can be explained by more risky behaviors in this population (food quality). Other studies have found that the incidence is associated with higher social status (Eberle et al., 2010), explained by the greater participation in colorectal cancer screening. 
In our study, we found no association between deprivation and colorectal cancer incidence, with relative risks very close to 1 , which hinders clarification of this contradiction. We can assume that the two conflicting influences lead to cancelation of any relationship.

Our study has some limitations. First, although our study population included all cases of cancer recorded in French registries between 2006 and 2009, this covers only 20\% of the French population, major French cities (Paris, Marseille, Lyon) are not covered by the registries, and the study area is not representative of the national territory for deprivation. Indeed, registries in France are defined at the local level and a national registry does not exist. Second, our study period started in 2006, when registries began to routinely record patient addresses for geocoding to assign each patient to an IRIS. Shortening the study period allowed us to include all the French registries, but prevented us from conducting temporal trend analysis. Despite the diversity and number of territories covered in the analysis may result in great heterogeneity of results, in fact, this was not the case. By comparing the analyses by department, similar results were obtained, suggesting comparability in terms of cancer registration between registries and lending consistency to our results. Moreover, this comparison didn't allow us to highlight a particular social situation in departments, for instance, regional measures for screening and prevention.

Some methodological aspects can be discussed. First, our study design used aggregate data at the IRIS level, with an ecological index of social deprivation. Although this type of index presents many advantages such as applicability to all populations, thus preventing selection bias, its main weakness is unavoidable ecological bias because the same score is assigned to all people living in the same area. However, this bias is limited by the use of IRIS, which is the smallest geographic level with available census data. ${ }^{23}$ Moreover, the relevance of ecological indices is not confined to being a "proxy" of individual social characteristics, because the potential effects of social characteristics of areas themselves are integrated, i.e., contextual effects. For example, with respect to lung cancer, such an index can account for the potentially higher levels of air pollution in deprived areas (Naess et al., 2007). 
In addition, the EDI used in this paper integrates subjective and objective dimensions of poverty. The EDI is based on the pioneering Townsend index concept of relative deprivation and is constructed with a common European database, enabling international analyses in Europe to be compared. The spatial nature of the data and its specificities (spatial autocorrelation and non-spatially structured heterogeneity) was accounted in our modeling thanks to the Bayesian approach ensuring a good consistency of the statistical analysis. Thus use of a classical Poisson regression would have risked to underestimate the standard error and to wrongly conclude at a significant effect of deprivation on cancer incidence (Haining et al., 2009).

Since the most important relative risks are observed for cancers of the lung, lips-mouth-pharynx and larynx, our results suggest that tobacco, which has already been identified as the number one enemy of public health, is also the most important carrier of social inequalities in cancer incidence. Moreover, since these socially determined cancers are also those with the poorest prognosis, which decreases further down the social scale, the social inequalities in incidence brought about by tobacco are also at the root of social inequalities in cancer mortality. To tackle such inequalities, our results therefore reinforce the urgent need to strengthen prevention efforts focused on tobacco consumption in the most at-risk populations. We must be aware that such prevention policies should act on inequalities themselves and therefore on the disadvantaged environment by increasing urbanization, transport, employment and not be limited to health interventions such as for reimbursement of nicotinic substitutes for example. Other risk factors should also be subject to specific measures, such as alcohol consumption, occupational risk factors and sexual risk factors, although with less urgency than tobacco. Concerning sites with over-incidence in affluent areas, it appears that individual over-risks are quite low; however, the impact on public health is important because the cancer sites concerned are the most frequent in the population (prostate and breast cancers). It is therefore important to measure the factors responsible for this phenomenon, such as over-diagnosis. 
By estimating the burden of social deprivation on cancer incidence with a site-specific approach, it is possible to better identify the kinds of public health measures appropriate for reducing social inequalities. The use of geographical approaches with relevant deprivation indices also permits us to better identify populations that should be targeted in such prevention efforts.

\section{Acknowledgments}

We thank the staff of each member registry of the FRANCIM network that participated in the collection of data.

\section{Ethics}

The study protocol was approved by French ethical committees, the CCTIRS (Comité Consultatif Sur le Traitement de l'Information) and CNIL (Commission Nationale de l'Informatique et des Libertés) (Authorization $\left.\mathrm{N}^{\circ} 913013\right)$.

\section{References}

Aarts MJ, Lemmens VE, Louwman MW, Kunst AE, Coebergh JW W. Socioeconomic status and changing inequalities in colorectal cancer? A review of the associations with risk, treatment and outcome. Eur J Cancer 2010; 46(15):2681-2695.

Adimora AA, Schoenbach VJ. Social context, sexual networks, and racial disparities in rates of sexually transmitted infections. J Infect Dis 2005; 191(Supp 1) :S115-S122.

Baumann M, Spitz E, Guillemin F, Ravaud JF, Choquet M, Falissard B,et al. Associations of social and material deprivation with tobacco, alcohol, and psychotropic drug use, and gender: a population-based study. Int J Health Geogr 2007; 6(1):50.

Benard VB, Johnson CJ, Thompson TD, Roland KB, Lai SM, Cokkinides V, et al. Examining the association between socioeconomic status and potential human papillomavirus-associated cancers. Cancer 2008; 113(S10):2910-2918. 
Binder-Foucard, F, Belot A, Delafosse P, Remontet, L, Woronoff, AS,Bossard N. Estimation nationale de l'incidence et de la mortalité par cancer en France entre 1980 et 2012. Registres des cancers 2013.

Boscoe FP, Johnson CJ, Sherman RL, Stinchcomb DG, Lin G, Henry KA. The relationship between area poverty rate and site-specific cancer incidence in the United States. Cancer 2014; 120(14):2191-2198.

Chang TS, Chang CM, Hsu TW, Lin YS, Lai NS, Su YC, et al. The combined effect of individual and neighborhood socioeconomic status on nasopharyngeal cancer survival. PloS one 2013; 8(9):e73889.

Cheng I, Witte JS, McClure LA, Shema SJ, Cockburn MG, John EM, et al. Socioeconomic status and prostate cancer incidence and mortality rates among the diverse population of California. Cancer Causes Control 2009; 20(8):1431-1440.

Colonna, M. Influence des paramètres a priori dans l'estimation bayésienne de risques relatifs. Analyse spatiale du cancer de la vessie dans l'agglomération grenobloise. Rev Epidemiol Sante Publique 2002 ; 54(6):529-542.

Cramer DW. The epidemiology of endometrial and ovarian cancer. Hematol Oncol Clin North $\operatorname{Am} 2012 ; 26(1): 1-12$

Dalton SO, Schüz J, Engholm G, Johansen C, Kjaer SK, Steding-Jessen M, et al. Social inequality in incidence of and survival from cancer in a population-based study in Denmark, 1994-2003: summary of findings. Eur J Cancer 2008; 44(14):2074-2085.

Eberle A, Luttmann S, Foraita R, Pohlabeln H. Socioeconomic inequalities in cancer incidence and mortality - a spatial analysis in Bremen, Germany. J Public Health 2010; 18(3):227-235.

Haining R, Law J, Griffith D. Modelling small area counts in the presence of overdispersion and spatial autocorrelation. Comput Stat Data An 2009, 53:2923-37. 
Hausauer AK, Swetter SM, Cockburn MG, Clarke CA. Increases in melanoma among adolescent girls and young women in California: trends by socioeconomic status and UV radiation exposure. Arch dermatol 2011; 147(7):783-789.

Hwang E, Johnson-Obaseki S, McDonald JT, Connell C, Corsten M. Incidence of head and neck cancer and socioeconomic status in Canada from 1992 to 2007. Oral Oncol 2013; 49(11):10721076.

Hystad P, Carpiano RM, Demers PA, Johnson KC, Brauer M. Neighbourhood socioeconomic status and individual lung cancer risk: Evaluating long-term exposure measures and mediating mechanisms. Soc Sci Med 2013; 97:95-103.

Krieger N, Williams D, Moss N. Measuring social class in US public health research: concepts, methodologies, and guidelines. Annu Rev Public Health 1997;18:341-78.

Krieger N, Chen JT, Waterman PD, Soobader MJ, Subramanian SV, Carson R. Geocoding and monitoring of US socioeconomic inequalities in mortality and cancer incidence: does the choice of area-based measure and geographic level matter? The Public Health Disparities Geocoding Project. Am J Epidemiol 2002; 156(5):471-482.

Lakshman R, McConville A, How S, Flowers J, Wareham N, Cosford P. Association between area-level socioeconomic deprivation and a cluster of behavioural risk factors: cross-sectional, population-based study. J Public Health 2011; 33(2):234-245.

Levi Z, Kark JD, Shamiss A, Derazne E, Tzur D, Keinan-Boker L, et al. Body mass index and socioeconomic status measured in adolescence, country of origin, and the incidence of gastroesophageal adenocarcinoma in a cohort of 1 million men. Cancer $2013 ; \mathbf{1 1 9 ( 2 3 ) : 4 0 8 6 - 4 0 9 3 . ~}$ Mackenbach JP, Stirbu I, Roskam AJR, Schaap MM, Menvielle G, Leinsalu M, et al. Socioeconomic inequalities in health in 22 European countries. N Engl J Med 2008; 358(23):24682481.

Maisonneuve P, Lowenfels AB. Risk factors for pancreatic cancer: a summary review of metaanalytical studies. Int J Epidemiol 2014; dyu240. 
McGlynn KA, Trabert B. Adolescent and adult risk factors for testicular cancer. Nat Rev Urol 2012; 9(6):339-349.

Meffre C, Le Strat Y, Delarocque-Astagneau E, Dubois F, Antona D, Lemasson JM, et al. Prevalence of hepatitis B and hepatitis C virus infections in France in 2004: social factors are important predictors after adjusting for known risk factors. J Med Virol 2010; 82(4):546-555.

Morgan RM, Steele RJ, Nabi G, McCowan C. Socioeconomic variation and prostate specific antigen testing in the community: a United Kingdom based population study. The J Urol 2013; 190(4):1207-1212.

Næss $\varnothing$, Piro FN, Nafstad P, Smith GD, Leyland AH. Air pollution, social deprivation, and mortality: a multilevel cohort study. Epidemiology 2007, 18(6), 686-694

Pascutto C, Wakefield JC, Best NG, Richardson S, Bernardinelli L, Staines A, et al. Statistical issues in the analysis of disease mapping data. Stat in Med 2000; 19(17-18):2493-2519.

Plan Cancer 2014-2019 : http ://www.e-cancer.fr/le-plan-cancer

Pornet C, Delpierre C, Dejardin O, Grosclaude P, Launay L, Guittet L, et al. Construction of an adaptable European transnational ecological deprivation index: the French version. J Epidemiol Community Health 2012;66:982-89.

Potthoff RF, Whittinghill M. Testing for homogeneity: II. The Poisson distribution. Biometrika $1966 ; 183-190$.

Robert SA, Trentham-Dietz A, Hampton JM, McElroy JA, Newcomb PA, et al. Socioeconomic risk factors for breast cancer: distinguishing individual-and community-level effects. Epidemiology 2004; 15(4):442-450.

Schmeisser N, Conway DI, Stang A, Jahn I, Stegmaier C, Baumgardt-Elms C, et al. A populationbased case-control study on social factors and risk of testicular germ cell tumours. BMJ open 2013; 3(9):e003833. 
Sharpe KH, McMahon AD, Raab GM, Brewster DH, Conway DI. Association between socioeconomic factors and cancer risk: a population cohort study in Scotland (1991-2006). PloS one 2014;9(2):e89513.

Shohaimi S, Welch A, Bingham S, Luben R, Day N, Wareham N, et al. Residential area deprivation predicts fruit and vegetable consumption independently of individual educational level and occupational social class: a cross sectional population study in the Norfolk cohort of the European Prospective Investigation into Cancer (EPIC-Norfolk). J Epidemiol Community Health 2004; 58(8):686-691.

Townsend P. Deprivation. J Soc Pol 1987;16:125-46.

Wakefield JC, Kelsall JE, Morris SE. Clustering, cluster detection, and spatial variation in risk. Spatial Epidemiol: methods and applications 2000; 128-152.

\section{Figure legend}

Figure 1 Relative risks of the most deprived category compared with the most affluent category and its $95 \%$ credible interval in men and in women 
Table 1 Site definition and frequencies in member registries of the FRANCIM network between 2006 and 2009

\begin{tabular}{|c|c|c|c|c|c|}
\hline \multirow[t]{2}{*}{ Site } & \multicolumn{2}{|l|}{ ICD-O-3a } & \multicolumn{3}{|c|}{ Frequencies } \\
\hline & Topography $^{b}$ & Morphology ${ }^{b}$ & Men & Women & Total \\
\hline Colon-Rectum & $\mathrm{C} 18, \mathrm{C} 19, \mathrm{C} 20, \mathrm{C} 21$ & All & 15747 & 12841 & 28588 \\
\hline Cervix & C53 & All & & 1823 & 1823 \\
\hline Uterus & C54 & All & & 3860 & 3860 \\
\hline Stomach & C16 & All & 3296 & 1840 & 5136 \\
\hline Liver & $\mathrm{C} 22$ & All & 4720 & 1043 & 5763 \\
\hline Larynx & C32 & All & 1735 & & 1735 \\
\hline Lips-Mouth-Pharynx & $\begin{array}{l}\mathrm{C} 0, \mathrm{C} 10, \mathrm{C} 11, \\
\mathrm{C} 12, \mathrm{C} 13, \mathrm{C} 14\end{array}$ & All & 5859 & 1469 & 7328 \\
\hline Lymphocytic leukemia & All & 98233 & 1538 & 1086 & 2624 \\
\hline Diffuse large-B-cell lymphoma & All & 96803 & 1359 & & 1359 \\
\hline Melanoma & C44 & 87203-87803 & 2950 & 3420 & 6370 \\
\hline Myeloma & All & $\begin{array}{l}97313-97343 \text { or } \\
97603-97643\end{array}$ & 1817 & 1535 & 3352 \\
\hline Esophagus & C15 & All & 3128 & & 3128 \\
\hline Ovary & C56 & $\begin{array}{l}\text { All excluding } \\
\text { \{84423; 84513; } \\
84613 ; 84623 ; \\
84723 ; 84733\}\end{array}$ & & 2721 & 2721 \\
\hline Pancreas & $\mathrm{C} 25$ & All & 3130 & 2950 & 6080 \\
\hline Lung & C33, C34 & All & 14908 & 4451 & 19359 \\
\hline Prostate & C61 & All & 34223 & & 34223 \\
\hline Kidney & $\mathrm{C} 64, \mathrm{C} 65, \mathrm{C} 66$ & All & 6175 & 2068 & 8243 \\
\hline Breast & C50 & All & & 29600 & 29600 \\
\hline Central nervous system & $\mathrm{C} 70, \mathrm{C} 71, \mathrm{C} 72$ & $\leq 91103$ or $\leq 91800$ & 2172 & 2486 & 4658 \\
\hline Myelodysplasic syndrome & All & $\begin{array}{l}99803,99823, \\
99833,99853, \\
99863,99873, \\
99893\end{array}$ & & 1090 & 1090 \\
\hline Testis & C62 & All & 1245 & & 1245 \\
\hline Thyroid & $\mathrm{C} 73$ & All & 1040 & 3291 & 4331 \\
\hline Bladder & C67 & All & 5257 & 1271 & 6528 \\
\hline
\end{tabular}

a ICD-0-3: International Classification of Diseases for Oncology, $3^{\text {rd }}$ Edition

${ }^{\mathrm{b}}$ Hematological codes are always excluded from solid tumor sites and included in the relevant hematological site 
Table 2 Influence of socioeconomic status on incidence of cancers in men, in French registries between 2006 and 2009

\begin{tabular}{llll}
\hline Site & $\mathrm{PW}^{\mathrm{a}}$ test & $\begin{array}{l}\text { Estimation } \\
\text { EDl coefficient }\end{array}$ & $\mathrm{Cl}^{\mathrm{c}}(95 \%)$ \\
\hline Colon-Rectum & 0.005 & 0.003 & {$[-0.002 ; 0.007]$} \\
Stomach & 0.239 & $\mathbf{0 . 0 2 2}$ & {$[\mathbf{0 . 0 1 3 ; 0 . 0 3 1 ]}$} \\
Liver & 0.139 & $\mathbf{0 . 0 2 3}$ & {$[\mathbf{0 . 0 1 5 ; 0 . 0 3 0 ]}$} \\
Larynx & 0.346 & $\mathbf{0 . 0 3 5}$ & {$[\mathbf{0 . 0 2 3 ; 0 . 0 4 6 ]}$} \\
Lips-Mouth-Pharynx & 0.001 & $\mathbf{0 . 0 4 8}$ & {$[\mathbf{0 . 0 4 2 ; 0 . 0 5 5 ]}$} \\
Lymphocytic leukemia & 0.455 & -0.006 & {$[-0.021 ; 0.008]$} \\
Diffuse large-B-cell lymphoma & 0.756 & -0.004 & {$[-0.019 ; 0.011]$} \\
Melanoma & 0.431 & $-\mathbf{0 . 0 4 2}$ & {$[-\mathbf{0 . 0 5 3 ; - 0 . 0 3 1 ]}$} \\
Myeloma & 0.275 & 0.004 & {$[-0.0090 ; 0.016]$} \\
Esophagus & 0.010 & $\mathbf{0 . 0 2 7}$ & {$[\mathbf{0 . 0 1 7 ; 0 . 0 3 7 ]}$} \\
Pancreas & 0.250 & $\mathbf{0 . 0 1 1}$ & {$[\mathbf{0 . 0 0 1 ; 0 . 0 2 0 ]}$} \\
Lung & 0.001 & $\mathbf{0 . 0 3 9}$ & {$[\mathbf{0 . 0 3 4 ; 0 . 0 4 3 ]}$} \\
Prostate & 0.016 & $-\mathbf{0 . 0 1 5}$ & {$[-\mathbf{0 . 0 1 8 ; - 0 . 0 1 1 ]}$} \\
Kidney & 0.029 & -0.007 & {$[-0.014 ; 0.001]$} \\
Central nervous system & 0.717 & -0.006 & {$[-0.017 ; 0.006]$} \\
Testis & 0.786 & $\mathbf{- 0 . 0 1 5}$ & {$[-\mathbf{0 . 0 2 9 ; - 0 . 0 0 1 ]}$} \\
Thyroid & 0.246 & 0.006 & {$[-0.010 ; 0.021]$} \\
Bladder & 0.031 & $\mathbf{0 . 0 1 6}$ & {$[\mathbf{0 . 0 0 8 ; 0 . 0 2 3 ]}$} \\
\hline
\end{tabular}

a Potthoff-Whittinghill.

${ }^{\mathrm{b}}$ Estimation of the coefficient related to EDI (European Deprivation Index). Positive for over-incidence in deprived areas, negative otherwise.

c Significant Cls (credible intervals) are in bold type. 
Table 3 Influence of socioeconomic status on incidence of cancers in women, in French registries between 2006 and 2009

\begin{tabular}{|c|c|c|c|}
\hline Site & $\mathrm{PW}^{\mathrm{a}}$ test & $\begin{array}{l}\text { Estimation }^{\mathrm{b}} \\
\text { EDI coefficient }\end{array}$ & $\mathrm{Cl}^{\mathrm{C}}(95 \%)$ \\
\hline Colon-rectum & 0.001 & 0.001 & {$[-0.005 ; 0.005]$} \\
\hline Cervix & 0.446 & 0.034 & {$[0.024 ; 0.044]$} \\
\hline Uterus & 0.419 & -0.006 & {$[-0.015 ; 0.003]$} \\
\hline Stomach & 0.099 & 0.031 & {$[0.019 ; 0.043]$} \\
\hline Liver & 0.828 & 0.040 & {$[0.025 ; 0.054]$} \\
\hline Lips-Mouth-Pharynx & 0.031 & 0.033 & {$[0.021 ; 0.045]$} \\
\hline Lymphocytic leukemia & 0.748 & -0.004 & {$[-0.021 ; 0.012]$} \\
\hline Melanoma & 0.197 & -0.037 & {$[-0.047 ;-0.027]$} \\
\hline Myeloma & 0.403 & 0.002 & {$[-0.012 ; 0.016]$} \\
\hline Ovary & 0.885 & -0.019 & {$[-0.030 ;-0.009]$} \\
\hline Pancreas & 0.528 & 0.008 & {$[-0.002 ; 0.018]$} \\
\hline Lung & 0.061 & 0.028 & {$[0.020 ; 0.035]$} \\
\hline Kidney & 0.368 & -0.002 & {$[-0.014 ; 0.009]$} \\
\hline Breast & 0.073 & -0.010 & {$[-0.014 ;-0.007]$} \\
\hline Central nervous system & 0.354 & 0.005 & {$[-0.006 ; 0.015]$} \\
\hline Myelodysplasic syndrome & 0.191 & 0.003 & {$[-0.014 ; 0.020]$} \\
\hline Thyroid & 0.048 & -0.002 & {$[-0.011 ; 0.008]$} \\
\hline Bladder & 0.002 & 0.012 & {$[-0.003 ; 0.027]$} \\
\hline
\end{tabular}

a Potthoff-Whittinghill.

${ }^{\mathrm{b}}$ Estimation of the coefficient related to EDI (European Deprivation Index). Positive for over-incidence in deprived areas, negative otherwise.

c Significant Cls (credible intervals) are in bold type. 
Table 4: Analysis using the quintile version of EDI in males, in French registries between 2006 and 2009

\begin{tabular}{|c|c|c|c|c|c|c|c|}
\hline Site & Social category & $\mathrm{RR}$ & $\mathrm{Cl}(95 \%)$ & Site & Social category & $\mathrm{RR}$ & $\mathrm{Cl}(95 \%)$ \\
\hline \multirow[t]{5}{*}{ Colon-Rectum } & Highest social class & 1.00 & & Esophagus & Highest social class & 1.00 & \\
\hline & & 1.04 & {$[0.99 ; 1.10]$} & & & 1.05 & [0.94;1.19] \\
\hline & & 1.05 & {$[0.99 ; 1.11]$} & & & 1.14 & {$\left[\begin{array}{ll}1.01 & 1.28\end{array}\right]$} \\
\hline & & 1.02 & {$[0.97 ; 1.08]$} & & & 1.29 & {$[1.14 ; 1.45]$} \\
\hline & Lowest social class & 1.04 & {$[0.97 ; 1.10]$} & & Lowest social class & 1.48 & {$[1.31 ; 1.68]$} \\
\hline \multirow[t]{5}{*}{ Stomach } & Highest social class & 1.00 & & Pancreas & Highest social class & 1.00 & \\
\hline & & 1.02 & {$[0.92 ; 1.14]$} & & & 0.99 & {$[0.89 ; 1.11]$} \\
\hline & & 1.00 & {$[0.90 ; 1.12]$} & & & 1.02 & {$[0.91 ; 1.14]$} \\
\hline & & 1.08 & {$[0.96 ; 1.21]$} & & & 0.98 & {$[0.87 ; 1.09]$} \\
\hline & Lowest social class & 1.24 & {$[1.11 ; 1.39]$} & & Lowest social class & 1.10 & {$[0.98 ; 1.23]$} \\
\hline \multirow[t]{5}{*}{ Liver } & Highest social class & 1.00 & & Lung & Highest social class & 1.00 & \\
\hline & & 1.00 & {$[0.91 ; 1.09]$} & & & 1.11 & {$[1.05 ; 1.18]$} \\
\hline & & 1.03 & {$[0.94 ; 1.13]$} & & & 1.22 & {$[1.15 ; 1.29]$} \\
\hline & & 1.19 & {$[1.08 ; 1.30]$} & & & 1.31 & {$[1.23 ; 1.39]$} \\
\hline & Lowest social class & 1.25 & {$[1.13 ; 1.37]$} & & Lowest social class & 1.59 & {$[1.50 ; 1.68]$} \\
\hline \multirow[t]{5}{*}{ Larynx } & Highest social class & 1.00 & & Prostate & Highest social class & 1.00 & \\
\hline & & 1.19 & {$[1.02 ; 1.39]$} & & & 0.89 & {$[0.86 ; 0.93]$} \\
\hline & & 1.24 & {$[1.06 ; 1.46]$} & & & 0.91 & {$[0.87 ; 0.95]$} \\
\hline & & 1.33 & {$[1.13 ; 1.56]$} & & & 0.93 & {$[0.88 ; 0.96]$} \\
\hline & Lowest social class & 1.67 & {$[1.43 ; 1.95]$} & & Lowest social class & 0.86 & {$[0.83 ; 0.90]$} \\
\hline \multirow{5}{*}{$\begin{array}{l}\text { Lips-Mouth- } \\
\text { Pharynx }\end{array}$} & Highest social class & 1.00 & & Kidney & Highest social class & 1.00 & \\
\hline & & 1.18 & {$[1.08 ; 1.30]$} & & & 1.02 & {$[0.95 ; 1.11]$} \\
\hline & & 1.27 & {$[1.16 ; 1.40]$} & & & 1.01 & {$[0.93 ; 1.10]$} \\
\hline & & 1.43 & {$[1.30 ; 1.57]$} & & & 1.03 & {$[0.95 ; 1.13]$} \\
\hline & Lowest social class & 1.89 & {$[1.72 ; 2.07]$} & & Lowest social class & 0.96 & {$[0.88 ; 1.05]$} \\
\hline \multirow{5}{*}{$\begin{array}{l}\text { Lymphocytic } \\
\text { leukemia }\end{array}$} & Highest social class & 1.00 & & Central & Highest social class & 1.00 & \\
\hline & & 1.00 & {$[0.86 ; 1.17]$} & Nervous & & 0.88 & {$[0.77 ; 1.01]$} \\
\hline & & 0.99 & {$[0.85 ; 1.16]$} & System & & 0.89 & {$[0.78 ; 1.02]$} \\
\hline & & 0.96 & {$[0.82 ; 1.13]$} & & & 0.95 & {$[0.83 ; 1.08]$} \\
\hline & Lowest social class & 1.00 & {$[0.85 ; 1.18]$} & & Lowest social class & 0.92 & {$[0.80 ; 1.05]$} \\
\hline \multirow{5}{*}{$\begin{array}{l}\text { Diffuse large-B- } \\
\text { cell lymphoma }\end{array}$} & Highest social class & 1.00 & & Testis & Highest social class & 1.00 & \\
\hline & & 1.05 & {$[0.90 ; 1.24]$} & & & 0.94 & {$[0.79 ; 1.14]$} \\
\hline & & 0.98 & {$[0.83 ; 1.16]$} & & & 0.96 & {$[0.79 ; 1.16]$} \\
\hline & & 0.96 & {$[0.81 ; 1.14]$} & & & 0.77 & {$[0.65 ; 0.92]$} \\
\hline & Lowest social class & 0.97 & {$[0.81 ; 1.15]$} & & Lowest social class & 0.85 & {$[1.01 ; 0.71]$} \\
\hline \multirow[t]{5}{*}{ Melanoma } & Highest social class & 1.00 & & Thyroid & Highest social class & 1.00 & \\
\hline & & 0.81 & {$[0.71 ; 0.91]$} & & & 1.01 & {$[0.84 ; 1.21]$} \\
\hline & & 0.84 & {$[0.74 ; 0.95]$} & & & 0.96 & {$[0.79 ; 1.16]$} \\
\hline & & 0.85 & {$[0.75 ; 0.96]$} & & & 1.11 & {$[0.84 ; 1.25]$} \\
\hline & Lowest social class & 0.72 & {$[0.64 ; 0.81]$} & & Lowest social class & 1.04 & {$[0.85 ; 1.26]$} \\
\hline \multirow[t]{5}{*}{ Myeloma } & Highest social class & 1.00 & & Bladder & Highest social class & 1.00 & \\
\hline & & 1.02 & {$[0.88 ; 1.17]$} & & & 1.08 & {$[0.98 ; 1.18]$} \\
\hline & & 1.01 & [0.87 1.17] & & & 1.11 & {$[1.01 ; 1.22]$} \\
\hline & & 1.00 & {$[0.86 ; 1.16]$} & & & 1.13 & {$[1.03 ; 1.24]$} \\
\hline & Lowest social class & 1.00 & {$[0.86 ; 1.16]$} & & Lowest social class & 1.22 & {$[1.11 ; 1.34]$} \\
\hline
\end{tabular}

Abbreviations: EDI: European Deprivation Index; RR: Relative risk; $\mathrm{Cl}$, Credible interval

aRRs calculated with the highest social class as reference 
Table 5 Analysis using the quintile version of EDI in women, in French registries between 2006 and 2009

\begin{tabular}{|c|c|c|c|c|c|c|c|}
\hline Site & Social category & $\mathrm{RR}$ & $\mathrm{Cl}(95 \%)$ & Site & Social category & $\mathrm{RR}$ & $\mathrm{Cl}(95 \%)$ \\
\hline \multirow[t]{5}{*}{ Colon-rectum } & Highest social class & 1.00 & & Ovary & Highest social class & 1.00 & \\
\hline & & 1.01 & {$[0.95 ; 1.07]$} & & & 0.82 & {$[0.72 ; 0.93]$} \\
\hline & & 0.99 & {$[0.93 ; 1.05]$} & & & 0.80 & {$[0.70 ; 0.90]$} \\
\hline & & 1.00 & {$[0.94 ; 1.06]$} & & & 0.79 & {$[0.70 ; 0.89]$} \\
\hline & Lowest social class & 1.01 & {$[0.95 ; 1.07]$} & & Lowest social class & 0.79 & {$[0.70 ; 0.90]$} \\
\hline \multirow[t]{5}{*}{ Cervix } & Highest social class & 1.00 & & Pancreas & Highest social class & 1.00 & \\
\hline & & 1.21 & {$[1.03 ; 1.41]$} & & & 1.04 & {$[0.92 ; 1.18]$} \\
\hline & & 1.27 & {$[1.08 ; 1.48]$} & & & 1.06 & {$[0.94 ; 1.20]$} \\
\hline & & 1.21 & {$[1.03 ; 1.42]$} & & & 1.13 & {$[1.00 ; 1.27]$} \\
\hline & Lowest social class & 1.62 & {$[1.40 ; 1.88]$} & & Lowest social class & 1.11 & {$[0.99 ; 1.26]$} \\
\hline \multirow[t]{5}{*}{ Uterus } & Highest social class & 1.00 & & Lung & Highest social class & 1.00 & \\
\hline & & 0.98 & {$[0.89 ; 1.09]$} & & & 1.12 & {$[1.01 ; 1.24]$} \\
\hline & & 1.01 & {$[0.91 ; 1.12]$} & & & 1.13 & {$[1.02 ; 1.26]$} \\
\hline & & 0.96 & {$[0.87 ; 1.07]$} & & & 1.24 & {$[1.12 ; 1.37]$} \\
\hline & Lowest social class & 0.97 & {$[0.87 ; 1.07]$} & & Lowest social class & 1.35 & {$[1.22 ; 1.49]$} \\
\hline \multirow[t]{5}{*}{ Stomach } & Highest social class & 1.00 & & Kidney & Highest social class & 1.00 & \\
\hline & & 1.16 & {$[1.00 ; 1.36]$} & & & 1.13 & {$[0.99 ; 1.30]$} \\
\hline & & 1.16 & {$[0.99 ; 1.35]$} & & & 1.03 & {$[0.89 ; 1.18]$} \\
\hline & & 1.24 & {$[1.06 ; 1.45]$} & & & 1.01 & {$[0.87 ; 1.16]$} \\
\hline & Lowest social class & 1.40 & {$[1.20 ; 1.63]$} & & Lowest social class & 1.00 & {$[0.87 ; 1.16]$} \\
\hline \multirow[t]{5}{*}{ Liver } & Highest social class & 1.00 & & Breast & Highest social class & 1.00 & \\
\hline & & 1.03 & {$[0.84 ; 1.27]$} & & & 0.91 & {$[0.88 ; 0.94]$} \\
\hline & & 1.15 & {$[0.94 ; 1.41]$} & & & 0.94 & {$[0.91 ; 0.98]$} \\
\hline & & 1.11 & {$[0.91 ; 1.37]$} & & & 0.95 & {$[0.91 ; 0.99]$} \\
\hline & Lowest social class & 1.45 & {$[1.19 ; 1.77]$} & & Lowest social class & 0.93 & {$[0.89 ; 0.96]$} \\
\hline \multirow{5}{*}{$\begin{array}{l}\text { Lips-Mouth- } \\
\text { Pharynx }\end{array}$} & Highest social class & 1.00 & & Central & Highest social class & 1.00 & \\
\hline & & 1.15 & {$[0.96 ; 1.38]$} & Nervous & & 1.06 & {$[0.93 ; 1.21]$} \\
\hline & & 1.29 & {$[1.08 ; 1.55]$} & System & & 1.07 & {$[0.94 ; 1.21]$} \\
\hline & & 1.48 & {$[1.24 ; 1.76]$} & & & 1.10 & {$[0.97 ; 1.25]$} \\
\hline & Lowest social class & 1.56 & {$[1.30 ; 1.86]$} & & Lowest social class & 1.10 & {$[0.97 ; 1.25]$} \\
\hline \multirow{5}{*}{$\begin{array}{l}\text { Lymphocytic } \\
\text { leukemia }\end{array}$} & Highest social class & 1.00 & & Myelodysplasic & Highest social class & 1.00 & \\
\hline & & 1.08 & {$[0.89 ; 1.30]$} & Syndrom & & 1.02 & {$[0.83 ; 1.24]$} \\
\hline & & 0.99 & {$[0.81 ; 1.20]$} & & & 0.91 & {$[0.74 ; 1.11]$} \\
\hline & & 0.95 & {$[0.78 ; 1.16]$} & & & 1.04 & {$[0.86 ; 1.27]$} \\
\hline & Lowest social class & 0.96 & {$[0.79 ; 1.17]$} & & Lowest social class & 0.93 & {$[0.76 ; 1.14]$} \\
\hline \multirow[t]{5}{*}{ Melanoma } & Highest social class & 1.00 & & Thyroid & Highest social class & 1.00 & \\
\hline & & 0.79 & {$[0.70 ; 0.88]$} & & & 0.98 & {$[0.88 ; 1.10]$} \\
\hline & & 0.82 & {$[0.73 ; 0.93]$} & & & 0.91 & {$[0.81 ; 1.02]$} \\
\hline & & 0.82 & {$[0.73 ; 0.93]$} & & & 0.95 & {$[0.85 ; 1.07]$} \\
\hline & Lowest social class & 0.71 & {$[0.64 ; 0.80]$} & & Lowest social class & 0.96 & {$[0.85 ; 1.08]$} \\
\hline \multirow[t]{5}{*}{ Myeloma } & Highest social class & 1.00 & & Bladder & Highest social class & 1.00 & \\
\hline & & 1.11 & {$[0.94 ; 1.31]$} & & & 0.95 & {$[0.79 ; 1.15]$} \\
\hline & & 1.09 & {$[0.93 ; 1.19]$} & & & 0.97 & {$[0.80 ; 1.17]$} \\
\hline & & 1.07 & {$[0.90 ; 1.26]$} & & & 1.07 & {$[0.89 ; 1.29]$} \\
\hline & Lowest social class & 1.09 & {$[0.92 ; 1.19]$} & & Lowest social class & 1.08 & {$[0.90 ; 1.31]$} \\
\hline
\end{tabular}

Abbreviations: EDI: European Deprivation Index; RR: Relative risk; $\mathrm{Cl}$, Credible interval

aRRs calculated with the highest social class as reference 